\title{
Enantioselective aminocatalysis: Michael addition of unactivated ketones to nitroolefins catalyzed by D-fructose derived monofunctional primary amine
}

\author{
KHIANGTE VANLALDINPUIA ${ }^{\mathrm{a}, \mathrm{b}}$, PORAG BORA ${ }^{\mathrm{a}}$, GRACE BASUMATARY ${ }^{\mathrm{a}}$, \\ RAHUL MOHANTA ${ }^{\mathrm{a}}$ and GHANASHYAM BEZ ${ }^{\mathrm{a}, *}$ \\ ${ }^{a}$ Department of Chemistry, North Eastern Hill University, Shillong, Meghalaya 793 022, India \\ ${ }^{b}$ Department of Chemistry, Pacchunga University College, Aizawl, Mizoram 796 001, India \\ E-mail: ghanashyambez@yahoo.com
}

MS received 31 July 2017; revised 24 August 2017; accepted 3 September 2017; published online 25 September 2017

\begin{abstract}
Organocatalytic asymmetric Michael addition is considered among the most extensively studied, yet challenging stereoselective reactions due to the fact that the electrophilic prochiral carbon in Michael acceptor lies away from stereodirecting groups of the catalyst. Although there is a report on stereoselective organocatalysis in Michael addition employing monofunctional secondary amine, the use of monofunctional primary amine for the said reaction is not reported till date. In fact, no monofunctional aminocatalyst is reported yet for the synthesis $\gamma$-nitro carbonyl compounds. Here we report our preliminary results on the enantioselective Michael addition of different ketones to nitro olefins catalysed by monofunctional primary amine (1) derived from D-fructose.
\end{abstract}

Keywords. Stereoselective aminocatalysis; monofunctional amine; D-fructose; Michael addition; nitroalkene.

\section{Introduction}

Organocatalytic asymmetric Michael addition is one of the most extensively studied stereoselective reactions in recent years. The pioneering works of List $^{1}$ and Barbas ${ }^{2}$ on organocatalytic asymmetric Michael additions have inspired many investigations ${ }^{3-5}$ employing multifunctional amine catalysts such as amine-thioureas ${ }^{6-14}$ and substituted pyrrolidines. ${ }^{15-36}$ Carbohydrate is one of the most enticing class of nature's chiral pools due to their chiral backbone that helps in stereochemical induction. In 2008, Zhou et al., reported the advantage of using bifunctional thiourea organocatalysts derived from $\alpha$ D-glucopyranose, galactose and lactose for asymmetric Michael addition of acetyl acetone to nitro olefins giving up to $>99 \%$ yield and up to $96 \%$ enantioselectivity. ${ }^{37}$ Benaglia et al., ${ }^{38}$ used another new class of glucosamine-based bifunctional organocatalysts for nucleophilic Michael addition of acetylacetone to nitro olefins and $N$-Boc imines of benzaldehyde to achieve up to $93 \%$ yield and $83 \%$ ee. More recently, Peddinti et al. ${ }^{39}$ and Shao et al., ${ }^{40,41}$ reported organocatalysts

\footnotetext{
*For correspondence
}

derived from $\alpha$-amino acids and carbohydrates for asymmetric Michael addition in solvent-free conditions. Given the importance of stereoselective Michael addition of carbonyl compounds to nitroalkenes ${ }^{42}$ in the synthesis of synthetically useful $\gamma$-nitro carbonyl compounds, ${ }^{43-45}$ Ma and co-workers reported bifunctional thiourea catalysts prepared from commercially available $\beta$-D-glucopyranose for a highly enantioselective Michael addition of aromatic ketones to nitroolefins. ${ }^{46}$

Even though the use of bifunctional amino catalysts is routine, there is only one report on the use of monofunctional amine for the said reaction. Gellman and $\mathrm{Chi}^{47}$ used diphenylprolinol methyl ether, a monofunctional secondary amine to catalyze intermolecular Michael addition of simple aldehydes to relatively non-activated enones with enantioselectivities up to $99 \%$ with catalyst loading of 1-5 mol\%. But the method worked best with catechol as a co-catalyst, which was believed to electrophilically activate the enone via hydrogen-bond donation to the carbonyl oxygen. Interestingly, stereoselective organocatalysis employing monofunctional primary amine is not reported till date. To our knowledge, no monofunctional aminocatalyst is reported yet for the synthesis $\gamma$-nitro carbonyl compounds as well. 


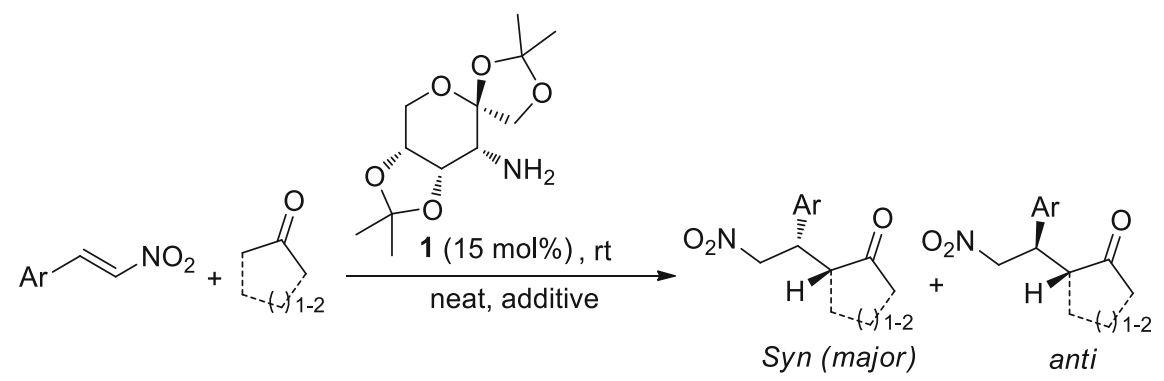

Scheme 1. Michael reaction catalysed by primary amine.

Therefore, we wish to report our preliminary results on the enantioselective Michael addition of different ketones to nitro olefins catalysed by monofunctional primary amine (1) derived from D-fructose (Scheme 1).

\section{Experimental}

\subsection{General remarks}

Chemicals and reagents were purchased from commercial sources and used without further purification. IR spectra were recorded on a Perkin-Elmer Spectrum One FTIR spectrometer. ${ }^{1} \mathrm{H}$ NMR $(400 \mathrm{MHz})$ and ${ }^{13} \mathrm{C}$ NMR (100 MHz) spectra were obtained on a Bruker AC-400 using $\mathrm{CDCl}_{3}$ as solvent and TMS as internal standard, unless otherwise stated. Mass spectra were obtained from Waters ZQ 4000 mass spectrometer by the ESI method, while the elemental analyses of the complexes were performed on a Perkin-Elmer-2400 CHN/S analyzer. Reactions were monitored by thin layer chromatography (TLC). The melting points of the compounds were recorded by open capillary method and were uncorrected. HPLC analysis was carried out on a Waters M515 equipped with Chiracel OD-H and Chiralcel AD-H columns using $n$ hexane and 2-propanol as mobile phase at room temperature.

\subsection{General procedure for Michael reaction}

A mixture of D-fructose derived amine $1(0.15 \mathrm{mmol})$, benzoic acid $(0.15 \mathrm{mmol})$ and ketone $(4 \mathrm{mmol} ; 10 \mathrm{mmol}$ in the case of acetone) were stirred at room temperature for $30 \mathrm{~min}$. Nitroolefin $(1 \mathrm{mmol})$ was then added. The reaction was allowed to run at room temperature and the progress of the reaction was monitored by thin layer chromatography. After the reaction was completed, saturated solution of ammonium chloride was added to the reaction mixture and stirred for another $10 \mathrm{~min}$. The compound was extracted with ethyl acetate $(3 \times 20 \mathrm{~mL})$, washed with water (3 times), dried over $\mathrm{Na}_{2} \mathrm{SO}_{4}$ and concentrated to get the crude product. The product obtained was further purified using flash column chromatography to obtain the pure Michael adduct.

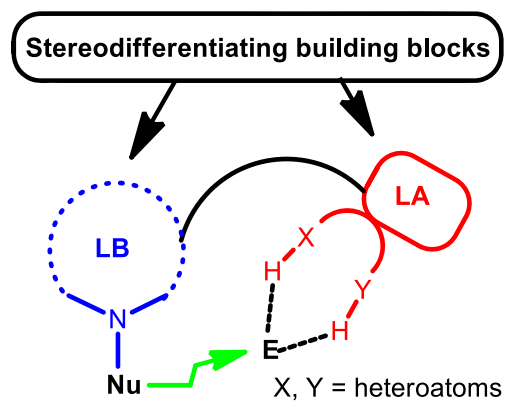

Figure 1. Aminocatalysis with bifunctional amine.

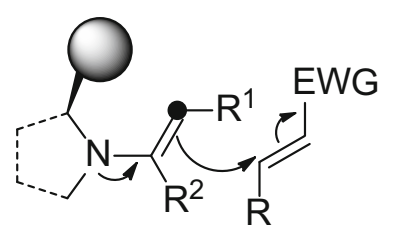

Figure 2. Aminocatalysis with monofunctional secondary amine.

\section{Results and Discussions}

In continuation of our report ${ }^{48}$ on aldol reaction employing D-fructose based amine $\mathbf{1}$ as organocatalyst, we wanted to extend the application of the catalysts 1-6 for direct Michael addition reactions. It may be noted that unlike aminocatalytic stereoselective Aldol and Henry reactions, where the stereodirecting group binds with carbonyl compound to facilitate the stereoselective 1, 2-addition reaction, the stereodirecting group bound to the Michael acceptor stays away from the electrophilic reaction centre, i.e., the carbon-carbon double bond. As a result, use of bifunctional organocatalysts is an absolute necessity in Michael type addition reaction where both the donor and acceptor molecule bind with the organocatalyst that comprises strategically placed stereodirecting cum activating groups to achieve the desired selectivity (Figures 1,2). 

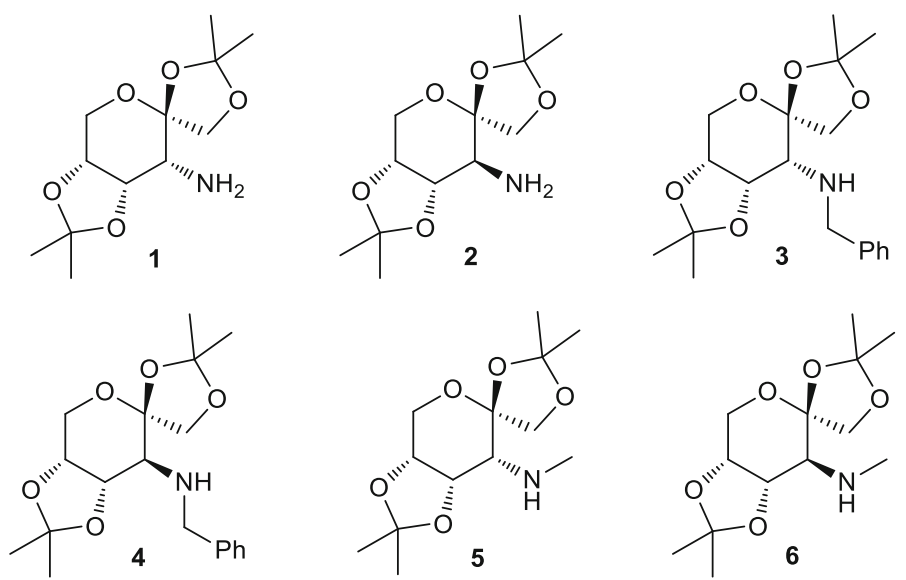

Figure 3. D-fructose derived amines.

Table 1. Solvents effect of asymmetric Michael reaction using sugar derived organocatalysts.

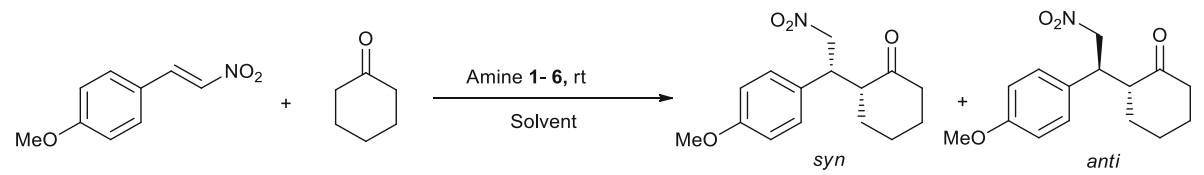

\begin{tabular}{|c|c|c|c|c|c|c|c|}
\hline Entry & Catalyst (15 mol\%) & Solvent & $t(\mathrm{~h})$ & Yield $\%^{a}$ & $d r^{\mathrm{b}}($ syn:anti $)$ & \multicolumn{2}{|c|}{$e e^{\mathrm{c}} \operatorname{syn}$ anti } \\
\hline 1 & 1 & Neat & 96 & 45 & $77: 23$ & 62 & 21 \\
\hline 2 & 2 & Neat & 96 & 57 & $47: 53$ & 16 & 31 \\
\hline 3 & $3 / 4 / 5 / 6$ & Neat & 120 & Trace & - & - & \\
\hline 4 & 1 & $\mathrm{CH}_{2} \mathrm{Cl}_{2}$ & 120 & 21 & $71: 29$ & 47 & 19 \\
\hline 5 & 1 & $\mathrm{CHCl}_{3}$ & 120 & Trace & $64: 36$ & 21 & 23 \\
\hline 6 & 1 & $\mathrm{DMSO} / \mathrm{DMF} / \mathrm{CH}_{3} \mathrm{CN} / \mathrm{H}_{2} \mathrm{O}$ & 120 & Trace & - & - & \\
\hline
\end{tabular}

Reaction condition: $p$-methoxy- $\beta$-nitrostyrene $(0.2 \mathrm{mmol})$, catalyst $(15 \mathrm{~mol} \%)$ and cyclohexanone $(0.8 \mathrm{mmol})$. ${ }^{\mathrm{a}}$ Isolated yields.

${ }^{b}$ Diastereoselectivity was determined by ${ }^{1} \mathrm{HNMR}$ of the crude product or HPLC analysis of the pure product.

${ }^{\mathrm{c}}$ Determined by HPLC analysis.

Given the fact that D-fructose based amines 1-6 possess the sugar backbone with two adjacent isopropylidene rings which may control the stereoselectivity of the Michael addition reaction similar to that of diphenylprolinol methyl ether, ${ }^{47}$ we screened the catalytic activity and stereoselectivity of the catalysts 1-6 (Figure 3) by taking the reaction of cyclohexanone and 4-methoxy $\beta$ nitrostyrene as the model reaction (Table 1). Moderate yield $(45 \%)$ with moderate diastereoselectivity (77:23 dr) and enantioselectivity (62\%) were obtained for syn product when the reaction was catalysed by 1 (Table 1 , entry 1).

When the model reaction was carried out with catalysts 2 under the neat reaction conditions, Michael product was obtained in 57\% yield with 47:53 diastereomeric ratio and $31 \%$ ee for the anti adduct. Consistent with our earlier observations in Aldol reaction, the fructose derived secondary amines 3-6 did not give any product under this reaction conditions (Table 1, entry 3) which led us to conclude that because of high steric congestion in secondary amines $\mathbf{3}-\mathbf{6}$, the catalysts carrying the primary amine may be more suitable to catalyze the reaction.

A series of solvents were screened (Table 1, entries 4-6) to confirm that the reaction gave the best result in the absence of solvents. Dichloromethane gave the best result among the solvents under scrutiny (Table 1, entry 4) giving $21 \%$ yield with $47 \%$ ee for the syn adduct. Although the reaction gave trace amount of the desired product with inferior stereoselectivity in $\mathrm{CHCl}_{3}$, the reaction did not work in other solvents at all (Table 1, entry 6). Catalyst 2 gave better result in term of yield, but the selectivity was rather poor (Table 1 , entry 2 ). Catalysts 3-6 having secondary amine functionality gave only trace amount of conversion even after stirring for $120 \mathrm{~h}$ which may be accounted for the high steric crowding around the amine group of the catalysts.

The influences of the amount of catalyst loading and addition of additive on a reaction were then examined. $15 \mathrm{~mol} \%$ catalyst loading was found to be optimum, 
Table 2. Monofunctional amine catalysed Michael addition reaction between cyclohexanone and $p$-methoxy- $\beta$-nitrostyrene.

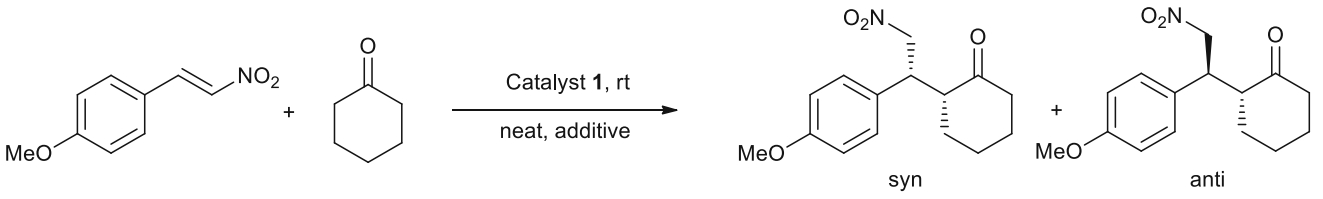

\begin{tabular}{llcrcccc}
\hline Entry & Catalyst $\mathbf{1}(\mathrm{mol} \%)$ & Additive & $t(\mathrm{~h})$ & Yield $\%^{\mathrm{a}}$ & $d r^{\mathrm{b}}($ syn:anti $)$ & $e e^{\mathrm{c}}$ syn & $e e^{\mathrm{c}}$ anti \\
\hline 1 & 15 & TFA & 36 & 67 & $60: 40$ & 33 & 11 \\
2 & 15 & $p-$ TsOH & 120 & $<10$ & - & - & 12 \\
3 & 15 & HOAc & 72 & 78 & $57: 43$ & 32 & 65 \\
4 & 15 & PhCOOH & 36 & 86 & $88: 12$ & 89 & 57 \\
5 & 20 & PhCOOH & 36 & 86 & $85: 15$ & 84 & 59 \\
6 & 10 & PhCOOH & 48 & 76 & $82: 18$ & 79 & 51 \\
7 & 5 & PhCOOH & 72 & 53 & $83: 17$ & 78 & \\
\hline
\end{tabular}

Reaction conditions: $p$-Methoxy- $\beta$-nitrostyrene $(0.2 \mathrm{mmol})$, catalyst $(15 \mathrm{~mol} \%)$, additive $(15 \mathrm{~mol} \%)$ and cyclohexanone $(0.8$ mmol).

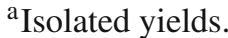

${ }^{b}$ Diastereoselectivity was determined by ${ }^{1} \mathrm{HNMR}$ of the crude product and validated with HPLC data.

${ }^{\mathrm{c}}$ Determined by HPLC analysis.

while its decrease to $5 \mathrm{~mol} \%$ and $10 \mathrm{~mol} \%$ negatively affected the reactivity as well as selectivity of the reaction (Table 2, entries 6-7). On the other hand, increasing the catalyst loading to $20 \mathrm{~mol} \%$ remained essentially the same as that of the reaction catalyzed by $15 \mathrm{~mol} \%$ of 1, while the enantioselectivity decreased slightly from $91 \%$ ee to $84 \%$ ee . Addition of additives such as TFA, HOAc and benzoic acids greatly enhanced the catalytic performance, probably by accelerating the formation of the enamine intermediate between the catalyst and the substrate. In fact, use of $15 \mathrm{~mol} \%$ catalyst 1 in the presence of $15 \mathrm{~mol} \%$ of benzoic acid under solvent free conditions was found to be optimum giving Michael adducts in $86 \%$ yield with $88: 12$ diastereoselective ratio and $89 \%$ enantiomeric excess in favour of the syn adduct (Table 2, entry 4). It is inexplicable to note that addition of $p$-TsOH deactivates the reaction as it gave the product in less than $10 \%$ yield (Table 2, entry 2).

With the optimal reaction conditions in hand, the reaction was carried out on a diverse range of substrates to explore the general applicability of this asymmetric transformation. As shown in Table 3 (entries 1-13), high isolated yields were obtained for all the products, regardless of the electronic nature of the aromatic substituents, and in most of the cases, syn products were obtained as the major product with moderate to high enantioselectivities.

When 1-[(E)-2-nitrovinyl]benzene was treated with cyclohexanone and benzoic acid in the presence of Dfructose derived 1,2:4,5-di- $O$-isopropylidene-3-amino3 -deoxy- $\alpha$-D-fructopyranose (1) as a catalyst, the product $7 \mathbf{a}$ was obtained in $92 \%$ yield after $24 \mathrm{~h}$ of stirring (Table 3, entry 1 ). When the same reaction conditions were applied to the addition of cyclopentanone to nitroolefins the time taken for completion of the reaction was much shorter in comparison to those with cyclohexanone (Table 3, entries 6-9). The reaction of various nitroalkenes with acetone in the presence of catalyst 1 showed excellent conversion with good enantioselectivity, albeit taking longer time than in the cases of cyclopentanone or cyclohexanone.

As far as the plausible mechanism of the reaction is concerned, it may be noted that the secondary amine can bind with carbonyl group to form iminium salt which readily tautomerizes to nucleophilic enamine. On the other hand, unless the enamine form is stabilized by further conjugation, either with an electron-withdrawing group ${ }^{49}$ or an aromatic nucleus, ${ }^{50}$ or by other less definite stabilizing factors, the reaction of primary amine with carbonyl compound leads to unfavourable imineenamine equilibrium that prefers the less nucleophilic imine form. Therefore, the use of monofunctional primary amine for stereoselective Michael addition poses considerable challenge with respect to (a) the lack of an activation site and stereodirecting group in the catalyst (Figure 2) for the Michael acceptor which is attacked by the Michael donor, i.e., the imine or enamine generated from the reaction of ketone with the amine catalyst; (b) formation of less reactive Michael donor in the form of imine (Figure 4).

The fact that the reaction of primary amine with carbonyl compound favours the less nucleophilic imine form, we carried out DFT calculation to see the stability of imine and enamine derived from the reaction of cyclohexanone with the catalyst $\mathbf{1}$. To our pleasure, it was observed that the enamine form $\mathbf{1 b}$ is more stable by 
Table 3. Asymmetric Michael addition reaction catalyzed by $\mathbf{1}$.

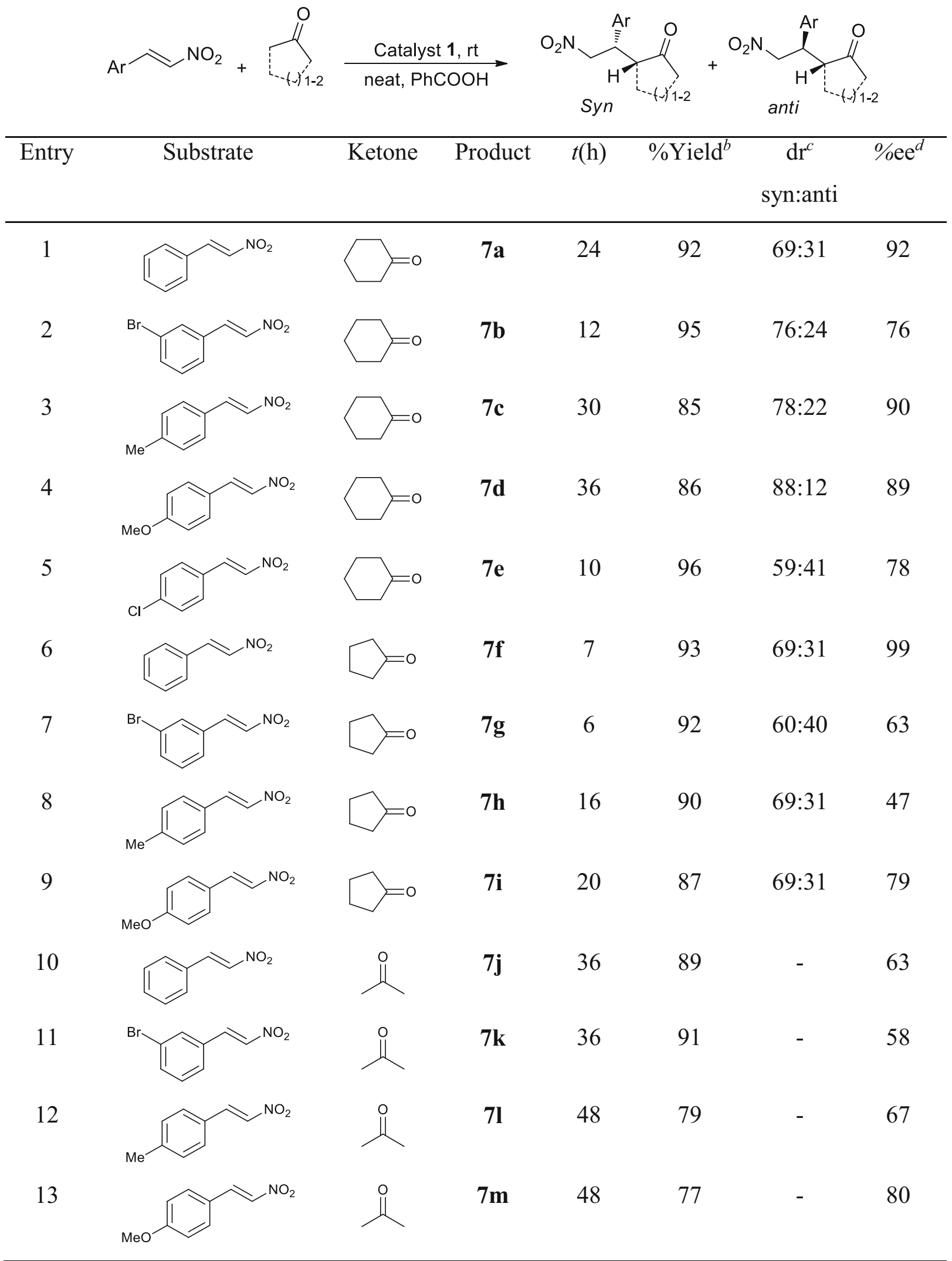

Reaction condition: Nitroolefin $(0.2 \mathrm{mmol})$, catalyst 1 (15 mol\%), PhCOOH (15 mol \%) and ketones $(0.8 \mathrm{mmol})$. ${ }^{\text {a } I s o l a t e d ~ y i e l d s . ~}$

${ }^{\mathrm{b}}$ Diastereoselectivity was determined by ${ }^{1}$ HNMR of the crude product.

${ }^{c}$ Enantioselectivity of the syn-diastereomer was determined by chiral HPLC analysis. 


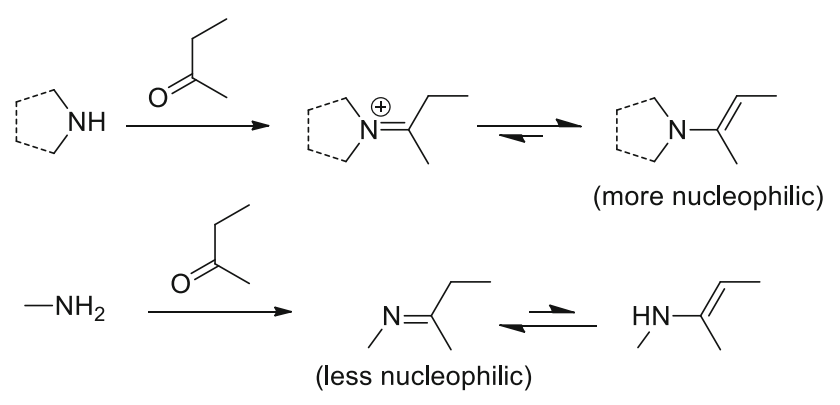

Figure 4. Enamine formation.
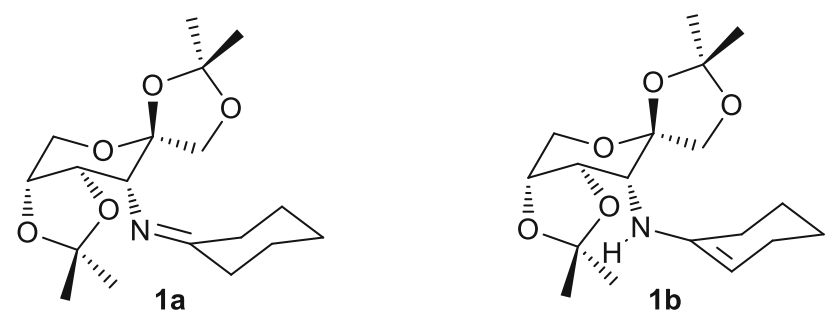

Figure 5. Structure of imine and enamine.

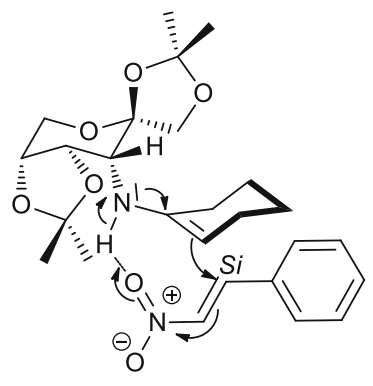

Syn (Favorable)

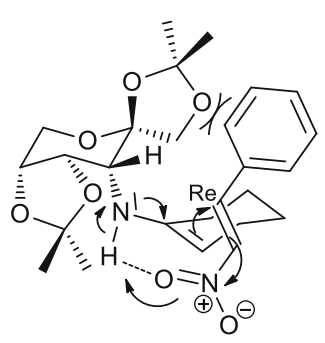

Anti (Less favorable)
Figure 6. Plausible mechanism of syn-selectivity.

$0.377 \mathrm{Kcal} / \mathrm{mol}^{51}$ than the imine form $1 \mathbf{a}$ (Figure 5). The shift in imine-enamine equilibrium to more nucleophilic enamine can be attributed to the lesser conformational restriction in enamine form in comparison to the imine.

As for the plausible mechanism of syn-selectivity, a tentative model representing the prototypical addition of cyclohexanone to trans- $\beta$-nitrostyrene in the presence of organocatalyst 1a might explain that the $\mathrm{NH}$ group of the enamine interacts through hydrogen bonding with the nitrogroup of the nitroalkene and enhances their electrophilicity. The $s i$-face approach to the nitroolefin, where the plan of the nitroolefin lies below plane of the enamine, generates syn-product while the re-face approach to the nitroolefin may be less favourable due steric interaction between the five-membered acetonide ring with the substituent on the $\beta$-position of the nitroolefin (Figure 6).
In conclusion, we have reported for the first time a stereoselective organocatalyst having only one activating group in the form of amine for asymmetric Michael addition of ketones to nitroolefins. Given the fact enamine derived from secondary amine is more nucleophilic, the favourable imine-enamine equilibrium in primary amine derived enamine is explained by DFT studies. While the D-Fructose derived primary amine, 1,2:4,5-di- $O$-isopropylidene-3-amino-3deoxy- $\alpha$-D-fructopyranose (1) has been found to be an effective catalyst for asymmetric Michael addition of ketones to nitroolefins giving up to $96 \%$ yield, 88:12 $d r$ and 89\% ee, while its opposite stereoisomer (2) was less reactive and selective under similar reaction conditions. Interestingly, fructose derived secondary amines $3,4,5$ and 6 were found to be ineffective for this transformation which may be due to steric hindrance.

\section{Supporting Information}

The spectroscopic data, ${ }^{1} \mathrm{HNMR}$ and ${ }^{13} \mathrm{CNMR}$ spectra of selected compounds, HPLC data and chromatogram, and computational data etc., are available free of charge via the Internet at http://www.ias.ac.in/chemsci.

\section{Acknowledgements}

Authors acknowledge the Council of Scientific and Industrial Research (CSIR), New Delhi, India for financial support (Scheme No. 1 (1992)/05/EMR-II). The analytical service provided by Sophisticated Analytical Instrument Facility, North Eastern Hill University, Shillong is gratefully acknowledged.

\section{References}

1. List B, Pojarlier P and Martin H J 2001 Efficient prolinecatalyzed Michael additions of unmodified ketones to nitro olefins Org. Lett. 32423

2. Betancort J M, Sakthivel K, Thayumanavan R and Barbas C F III. 2001 Catalytic enantioselective direct Michael additions of ketones to alkylidinemalonates Tetrahedron Lett. 424441

3. Krause N and Hoffmann-Röder A 2001 Recent advances in catalytic enantioselective Michael additions Synthesis 44171

4. Berner O M, Tedeschi L and Enders D 2002 Asymmetric Michael additions to nitroalkenes Eur. J. Org. Chem. 20021877

5. Christofers J and Baro A 2003 Construction of quaternary stereocenters: new perspectives through enantioselective Michael reactions Angew. Chem. Int. Ed. 421688

6. Kaprzak A and Gawronski J 2001 Review on the use of cinchona alkaloids as organic catalyst Synthesis 961 
7. Oare D A and Heathcock C H 1989 Stereochemistry of the base-promoted Michael addition reaction Top. Stereochem. 19242

8. Wu F, Hong R, Khan J, Liu X and Deng L 2006 Asymmetric synthesis of chiral aldehyde by conjugate additions with bifunctional organocatalysis by cinchona alkaloids Angew. Chem. Int. Ed. 454301

9. Wu F, Li H, Hong R, Deng L 2006 Construction of quaternary stereocenters by efficient and practical conjugate additions to $\alpha, \beta$-unsaturated ketones with a chiral organic catalyst Angew. Chem. Int. Ed. 45947

10. Brandes S, Niess B, Bella M, Prieto A, Overgaard J and Jorgensen K A 2006 Non-biaryl atropisomers in organocatalysis Chem. Eur. J. 126039

11. Bell M, Frisch K and Jorgensen K A 2006 Organocatalytic asymmetric deconjugative Michael additions $J$. Org. Chem. 715407

12. Takemoto Y 2005 Recognition and activation by ureas and thioureas: stereoselective reactions using ureas and thioureas as hydrogen-bonding donors Org. Biomol. Chem. 34299

13. Connon S J 2006 Organocatalysis mediated by thiourea derivatives Chem. Eur. J. 125418

14. Lu A, Gao P, Wu Y, Wang Y, Zhou Z and Tang C 2009 Highly enantio- and diastereoselective Michael addition of cyclohexanone to nitroolefins catalyzed by a chiral glucose-based bifunctional secondary amine-thiourea catalyst Org. Biomol. Chem. 73141

15. Huang H and Jacobsen E N 2006 Highly enantioselective direct conjugate addition of ketones to nitroalkenes promoted by achiral primary amine-thiourea catalyst $J$. Am. Chem. Soc. 1287170

16. Inokuma T, Hoashi $Y$ and Takemoto $Y 2006$ Thioureacatalyzed asymmetric Michael addition of activated methylene compounds to $\alpha, \beta$-unsaturated imides: dual activation of imide by intra- and intermolecular hydrogen bonding J. Am. Chem. Soc. 1289413

17. Wang Y-Q, Song J, Hong R, Li H and Deng L 2006 Asymmetric Friedel-Crafts reaction of indoles with imines by an organic catalyst J. Am. Chem. Soc. 128 8156

18. Luo S Z, Xu H, Mi X L, Li J Y, Zheng X X and Cheng J P 2006 Evolution of pyrrolidine-type asymmetric organocatalysts by "Click" chemistry J. Org. Chem. 719244

19. Cobb A J A, Longbottom D A, Shaw D M and Ley S V 2004 5-Pyrrolidin-2-yltetrazole as an asymmetric organocatalyst for the addition of ketones to nitro-olefins Chem. Commun. 1808

20. Mase N, Thayumanavan R, Tanaka F and Barbas C F III 2004 Direct asymmetric organocatalytic Michael reactions of $\alpha, \alpha$-disubstituted aldehydes with $\beta$-nitrostyrenes for the synthesis of quaternary carbon-containing products Org. Lett. 62527

21. Alexakis A and Andrey O 2002 Diamine-catalyzed asymmetric Michael additions of aldehydes and ketones to nitrostyrene $\mathrm{Org}$. Lett. 43611

22. Ishii T, Fujioka S, Sekiguchi Y and Kotsuki H 2004 A new class of chiral pyrrolidine-pyridine conjugate base catalysts for use in asymmetric Michael addition reactions J. Am. Chem. Soc. 1269558
23. Wang W, Wang J and Li H 2005 Direct, highly enantioselective pyrrolidinesulfonamide catalyzed Michael addition of aldehydes to nitrostyrenes Angew. Chem. Int. Ed. 441369

24. Cao C L, Ye M C, Sun X L and Tang Y 2006 Pyrrolidine-thiourea as a bifunctional organocatalyst: highly enantioselective Michael addition of cyclohexanone to nitroolefins Org. Lett. 82901

25. Hayashi Y, Gotoh H, Hayashi T and Shoji M 2005 Diphenylprolinolsilylethers as efficient organocatalysts for the asymmetric Michael reaction of aldehydes and nitroalkenes Angew. Chem. Int. Ed. $\mathbf{4 4} 4212$

26. Martin H J and List B 2003 Mining sequence space for asymmetric aminocatalysis: $N$-terminal prolylpeptides efficiently catalyze enantioselective Aldol and Michael reactions Synlett 1901

27. Palomo C, Vera S, Mielgo A and Gómez-Bengoa E 2006 Highly efficient asymmetric Michael addition of aldehydes to nitroalkenes catalyzed by a simple trans-4hydroxyprolylamide Angew. Chem. Int. Ed. 455984

28. Luo S Z, Mi X L, Song L Z, Xu H and Cheng J P 2006 Functionalized chiral ionic liquids as highly efficient asymmetric organocatalysts for Michael addition to nitroolefins Angew. Chem. Int. Ed. 453093

29. Luo S Z, Mi X L, Liu S, Xu H and Cheng J P 2006 Surfactant-type asymmetric organocatalyst: organocatalytic asymmetric Michael addition to nitrostyrenes in water Chem. Commun. 3687

30. Almasi D, Alonso D Aand Nájera C 2006 Enantioselective conjugate addition of ketones to $\beta$-nitrostyrenes catalyzed by 1,2-amino alcohol-derived prolinamides Tetrahedron: Asymm. 172064

31. Reyes E, Vicario J L, Badia D and Carrillo L 2006 Organocatalyticasymmetric Michael addition of aldehydes to $\beta$-nitroacroleine dimethylacetal Org. Lett. 86135

32. Clarke M L and Fuentes J A 2007 Self-assembly of organocatalysts: fine-tuning organocatalytic reactions Angew. Chem. Int. Ed. 46930

33. Barros M T and Phillips A M F 2007 Chiral piperazines as efficient catalysts for the asymmetric Michael addition of aldehydes to nitroalkenes Eur. J. Org. Chem. 178

34. Li P H, Wang L, Wang M and Zhang Y C 2008 Polymerimmobilized pyrrolidine-based chiral ionic liquids as recyclable organocatalysts for asymmetric Michael additions to nitrostyrenes under solvent-free reaction conditions Eur. J. Org. Chem. 1157

35. Mandal T and Zhao C G 2008 Modularlydesigned organocatalytic assemblies for direct Nitro Michael addition reactions Angew. Chem. Int. Ed. 477714

36. Xue F, Zhang S, Duan W and Wang W 2008 A novel bifunctional sulphonamide primary aminecatalyzedenantioselective conjugate addition of ketones to nitroolefins Adv. Synth. Catal. 3502194

37. Gao P, Wang C, Wu Y, Zhou Z and Tang C 2008 Sugarderived bifunctional thiourea organocatalyzed asymmetric Michael addition of acetylacetone to nitroolefins Eur. J. Org. Chem. 4563

38. Puglisi A, Benaglia M, Raimondi L, Lay L and Poletti L 2011 Novel carbohydrate-based bifunctional organocatalysts for nucleophilic addition to nitroolefins and imines Org. Biomol. Chem. 93295 
39. Agarwal J and Peddinti R K 2011 Asymmetric Michael addition catalysed by sugar-based prolinamides in solvent-free conditions Tetrahedron Lett. 52117

40. Pu X, Li P, Peng F, Li X, Zhang H and Shao Z2009 Asymmetric conjugate addition of acetylacetone to nitroolefins with chiral organocatalysts derived from both $\alpha$-amino acids and carbohydrates Eur. J. Org. Chem. 20094622

41. Pu X W, Peng F Z, Zhang H B and Shao Z H 2010 Doubly stereocontrolled asymmetric conjugate addition of acetylacetone to nitroolefins catalyzed by bifunctional tertiary amine-thiourea catalysts derived from both acyclic $\alpha$ amino acids and carbohydrates Tetrahedron $\mathbf{6 6} 3655$

42. Ishii T, Fujioka S, Sekiguchi S and Kotsuki H 2004 A new class of chiral pyrrolidine-pyridine conjugate base catalysts for use in asymmetric Michael addition reactions J. Am. Chem. Soc. 1269558

43. Ono N 2001 The Nitro Group in Organic Synthesis (New York: Wiley)

44. Calderari G and Seebach D 1985 Asymmetrische Michael-Additionen. Stereoselektive Alkylierung chiraler, nicht racemischer Enolate durch Nitroolefine. Herstellung enantiomerenreiner $\gamma$-Aminobuttersäure- und Bernsteinsäure-Derivate Helv. Chim. Acta 681592

45. Czekelius C and Carreira E M 2005 Convenient transformation of optically active nitroalkanes into chiral aldoximes and nitriles Angew. Chem. Int. Ed. 44612
46. Liu K, Cui H F, Nie J, Dong K Y, Li X J and Ma J A 2007 Highly enantioselective Michael addition of aromatic ketones to nitroolefinspromoted by chiral bifunctional primary amine-thioureacatalysts based on saccharides Org. Lett. 9923

47. Peelen T J, Chi Y and Gellman S H 2005 Enantioselective organocatalytic Michael additions of aldehydes to enones with imidazolidinones: Cocatalyst effects and evidence for an enamine intermediate $\mathrm{J}$. Am. Chem. Soc. 12711598

48. Vanlaldinpuia K, Bora P and Bez G 2017 Monofunctional primary amine: A new class of organocatalyst for asymmetric Aldol reaction J. Chem. Sci. 129301

49. Guingant A and Hammami H 1991 Synthesis of optically active $\alpha, \alpha$-disubstituted $\beta$-keto esters via chiral $\beta$-enamino esters Tetrahedron: Asym. 2411

50. Volpe T, Revial G, Pfau M and d'Angelo J 1987 Enantioselective synthesis of ring-C aromatic steroids by asymmetric Michael-type alkylation of chiral imines Tetrahedron Lett. 282367

51. DFT calculation by employing B3LYP/6-311++G (d, p) basis set shows that $\mathrm{E}_{1 \mathrm{a}}=-711641.498 \mathrm{Kcal} / \mathrm{mol}$ and $\mathrm{E}_{1 \mathrm{~b}}=-711641.875 \mathrm{Kcal} / \mathrm{mol}$. 